\title{
Are social prediction errors universal? Predicting compliance with a direct request across cultures
}

\author{
Vanessa K. Bohns ${ }^{1}$ \\ University of Toronto \\ Michel J.J. Handgraaf \\ University of Amsterdam \\ Jianmin Sun \\ Renmin University of China \\ Hillie Aaldering \\ University of Amsterdam \\ Changguo Mao \\ Renmin University of China \\ Jennifer Logg \\ Columbia University
}

\begin{abstract}
A B S T R A C T
Previous research conducted in the United States has demonstrated that help-seekers fail to appreciate the embarrassment and awkwardness (i.e., social costs) targets would experience by saying "no" to a request for help. Underestimation of such social costs leads help-seekers to underestimate the likelihood that others will comply with their requests. We hypothesized that this error would be attenuated in a collectivistic culture. We conducted a naturalistic helpseeking study in the U.S. and China and found that Chinese help-seekers were more accurate than American help-seekers at predicting compliance. A supplementary scenario study in which we measured individual differences in collectivistic and individualistic orientations within a single culture provided converging evidence for the association between collectivism and expectations of compliance. In both cases, the association between collectivism (culturally defined or measured) and predicted compliance was mediated by participants' ratings of the social costs of saying "no".
\end{abstract}

K E Y W O R D S Compliance, Cross-cultural differences Egocentrism Help-seeking Perspective-taking

1 Corresponding author. J. L. Rotman School of Management, University of Toronto, 105 St. George St. Toronto, ON M5S 3E6, Canada.

E-mail address: Vanessa.Bohns@rotman.utoronto.ca (V.K. Bohns). 
Politeness in responding to others' requests is considered a universal norm (Goffman, 1967; Grice, 1975). The likelihood that a request for help will be met with rudeness or refusal is slim, regardless of where one is in the world. However, research conducted in the United States has shown that people tend not to realize this fact when they are in the position of needing help (Flynn \& Lake (Bohns), 2008). Help-seekers focus on their own concerns rather than the social costs of saying "no" (how uncomfortable their targets would feel refusing a request). Thus, help-seekers typically underestimate the likelihood that others will comply with their requests.

We examined whether this egocentrically derived social prediction error would be attenuated in a more collectivistic culture. Previous research has demonstrated that help-seekers in collectivistic cultures tend to be more attuned than helpseekers in individualistic cultures to the instrumental costs helpers incur by saying "yes" to a request (i.e., the burden placed on helpers; e.g., Kim, Sherman, Ko, \& Taylor, 2006). We hypothesized that collectivistic help-seekers would similarly be more attuned to the social costs of saying "no" (the embarrassment targets would experience by saying "no"). Thus, we hypothesized that help-seekers in a more collectivistic culture would more accurately predict compliance than helpseekers in a more individualistic culture.

An important characteristic of individualistic cultures is an assumption that each individual is uniquely responsible for looking after his own personal needs and desires (Markus \& Kitayama, 1991; Triandis, 1995). Members of individualistic cultures are believed to act largely of their own volition - doing something only if it is consistent with their own personal wishes - rather than out of a sense of obligation or social pressure. Importantly, however, this assumption is often incorrect. Many studies have illustrated the ways in which members of individualistic cultures (usually Americans) can be compelled to engage in behaviors they do not personally enjoy or condone out of social pressures and/or fear of embarrassment (e.g., Asch, 1956; Milgram, 1963). Yet the general belief that others are acting out of personal volition persists, even when a person's behavior seems odd or questionable to outside observers (e.g., administering excessive electric shocks). In general, observers in individualistic cultures tend to discount face-saving concerns and social pressures as an explanation for others' behavior (Bohns \& Flynn, 2010; Sabini, Siepmann, \& Stein, 2001; Van Boven, Loewenstein, \& Dunning, 2005).

Within the context of helping, the assumption that an individual's behavior is independently motivated implies that when a person is asked for help, she will decide whether or not to help of her own free will, not out of any sense of obligation or coercion (Kim et al., 2006). Despite this assumption, social pressures and face-saving concerns do indeed drive the behavior of helpers, compelling them to comply with requests rather than suffer the awkwardness of saying "no." Yet, again, this fact seems to be lost on outside observers: help-seekers in individualistic cultures tend to neglect the face-saving concerns of potential helpers and consequently underestimate compliance (Flynn \& Lake (Bohns), 2008).

Conversely, a central tenet of collectivistic cultures is an assumption of interdependence (Markus \& Kitayama, 1991). Individuals are expected to place relational and group needs above personal needs (Kim \& Markus, 1999; Triandis, 1995). The corresponding assumption in helping contexts is that potential helpers are, in fact, generally obligated to say "yes." Members of collectivistic cultures are expected to help others even if helping is not in line with their own personal interests. Consequently, in collectivistic cultures it is the help-seeker's (not the potential helper's) responsibility to decide whether a particular request is worthwhile or whether he will unnecessarily burden a potential helper by asking (Kim, 
Sherman, \& Taylor, 2008). This expectation means that in addition to managing their own concerns, help-seekers in collectivistic cultures must also take into account the concerns of potential helpers.

We hypothesized that because help-seekers in collectivistic cultures are more attuned to the perspectives of potential helpers, in addition to rating the instrumental costs potential helpers would incur by agreeing to a request to be greater, they would also rate the social costs potential helpers would incur by refusing a request to be greater. That is, we predicted that help-seekers in more collectivistic cultures would be more attuned to the social pressures and face-saving concerns (the discomfort of saying "no") that would compel a target to agree to a request. Accordingly, help-seekers in more collectivistic cultures should be more accurate at predicting (i.e., less likely to underestimate) compliance than helpseekers in more individualistic cultures.

We initially tested this hypothesis by conducting a naturalistic help request study in two cultures that have been shown to vary in the extent to which collectivistic orientations predominate: China and the United States. To garner greater confidence that our findings were indeed driven by differences in the prevalence of collectivism between these two cultures, we conducted a supplementary scenario study in which we measured individualistic and collectivistic orientations within a single culture and looked at associations between these orientations and expectations of compliance.

\section{Study 1}

Study 1 was conducted at two large, renowned, cosmopolitan universities with comparable campuses and student bodies: Renmin University of China in Beijing ( $N=97 ; 70$ female), and Columbia University in New York City ( $N=82 ; 53$ female). Participants at each site made requests of passers-by after first predicting the likelihood that their targets would comply with their requests. All participants were recruited and compensated via standard procedures for each site, and no participants elected to withdraw from the study.

Participants initially received the following instructions, administered in the appropriate language for each site (English or Mandarin): "In this study, you will ask strangers (in person) for a favor. The favor you will be asking them to do is to fill out a paper-and-pen questionnaire that takes approximately 5-10 min to complete." After reviewing the questionnaire their targets would complete (which included filler items from several scales), participants received guidelines for making their requests. They had to obtain compliance from five different people, could approach only strangers, and had to follow a script ("Will you fill out a questionnaire?"), which was provided to them before they made their predictions. They were to record on a tally sheet the response ("yes" or "no") of every person they approached. The reliability of this procedure was vetted extensively by Flynn and Lake (Bohns) (2008) who found that participants consistently followed the instructed procedures.

\section{Predicted and actual compliance measures}

After reviewing the instructions, participants were asked, "How many people do you think you will have to approach before five people agree to fill out a questionnaire?" They were then sent outside and asked to return once they had accomplished their task. Participants' predictions were compared to the actual number of people they reported approaching as our measure of prediction accuracy. 
Perceived social costs of saying "no"

After making their predictions but before making their actual requests, participants completed a 4-item, 7-point scale measuring the perceived social costs of saying "no" to a request. Specifically, participants reported how difficult they thought it would be for targets to say "no" to their requests, and how bad, awkward, and embarrassed they thought potential helpers would feel saying "no" to their requests $(\alpha=.80)$.

Perceived instrumental costs of saying "yes"

Following previous work by Kim et al. (2006), we also included a proxy for the instrumental costs (the burden) of saying "yes" to this request. Participants rated on a 7-point scale how easy targets would find filling out a questionnaire.

\section{Results}

We expected to find that our Chinese help-seekers were more accurate at predicting compliance than our American help-seekers. Further, we hypothesized that any differences in prediction accuracy between the two samples would be mediated by their differential ratings of the social costs of saying "no" to a request for help. To test these predictions, we first conducted a mixed-model ANOVA with sample (China, U.S.) as the between-subjects factor and predicted versus actual compliance as repeated measures.

\section{Main effects}

We replicated the original underestimation of compliance effect. Across the two samples combined, the number of people participants predicted they would need to ask $(M=13.4, S D=8.5)$ was greater than the actual number of people they needed to ask $(M=7.5, S D=3.0), F(1,177)=92.7, p<.001, \eta^{2} p=.34$.

There were also main effects of culture on both actual and predicted compliance. Not surprisingly, our Chinese helpseekers actually had to ask fewer people for help to successfully get five people to comply $(M=6.7, S D=1.8)$ than did our American help-seekers $(M=8.3, S D=3.7), F(1,177)=14.07, p<.001, \eta^{2} p=.07$. Our Chinese help-seekers also predicted that they would have to ask fewer people $(M=10.8, S D=5.8)$ than did our American help-seekers $(M=16.1, S D=10.1)$, $F(1,177)=19.28, p<.001, \eta^{2} p=.10$. Importantly, this latter finding persisted when controlling for actual compliance, $\mathrm{F}(1,176)=14.5, p<.001$.

\section{Sample xaccuracy interaction}

As hypothesized, there was a significant interaction of sample with the predicted $\mathrm{x}$ actual compliance repeatedmeasure term, $F(1,177)=9.24, p=.003, \eta^{2} p=.05$, indicating that our Chinese help-seekers more accurately predicted compliance than our American help-seekers (Fig. 1). While our American help-seekers overestimated the number of people they would have to approach by an average of 7.8 people $(48.5 \%), F(1,177)=74.02, p<.001, \eta^{2} p=.30$, our Chinese help-seekers overestimated by only 4.1 people $(38.0 \%), F(1,177)=23.69, p<.001, \eta^{2} p=.12$.

To ensure that these findings were driven by differences in egocentric social prediction between the two samples, 
rather than real cultural differences in how normatively difficult it is for helpers to say "no," we reran the same mixedmodel ANOVA [samplex(predictedxactualcompliance)] with actual compliance as a covariate. After controlling for actual compliance, any residual effects can be attributed solely to crosscultural differences in egocentric social prediction. Again our hypothesis was confirmed, $\mathrm{F}(1,176)=14.45, p<.001$.

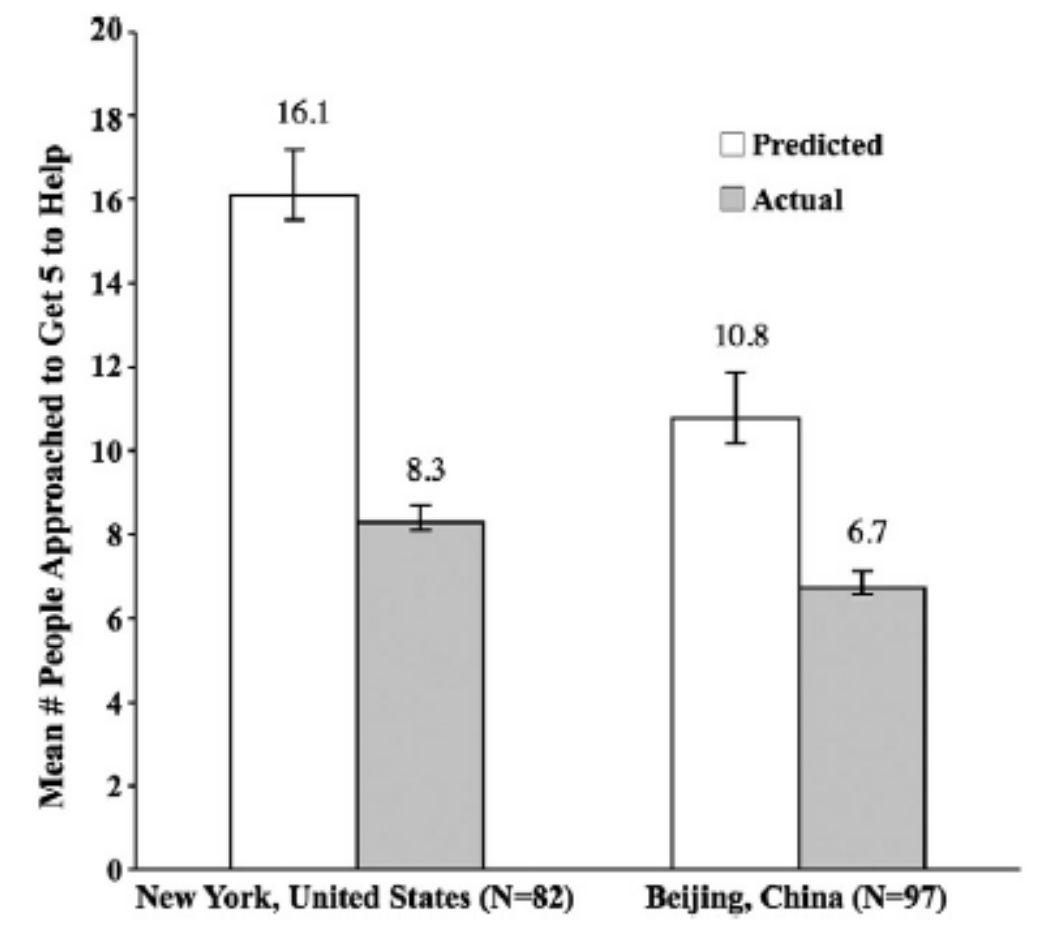

Fig. 1. Predicted versus actual compliance with a direct request for help in the United States and China (bars indicate \pm one standard error).

\section{Mediation by social costs}

Also as predicted, the samplexaccuracy interaction was mediated by participants' perceptions of the social costs of saying "no" to their requests. Our Beijing sample rated the social costs of saying "no" as greater $(M=3.33, S D=1.01)$ than did our New York sample $(M=2.83, S D=1.22), F(1,177)=9.41, p=.002, \eta^{2} p=.05$. Mediation was confirmed using Baron and Kenny's (1986) mediation procedure (Fig. 2) and by a Sobel (1982) test, $z=2.21, p=.03$.

\section{Instrumental costs}

Replicating the findings of Kim et al. (2006), Chinese requesters rated the instrumental costs of saying "yes" (the difficulty of the task) as significantly greater (i.e., less easy, $M=3.90, S D=1.26$ ) than did American requesters ( $M=4.73$, $S D=1.43), F(1,177)=17.71, p<.001, \eta^{2} p=.09$. However, perceptions of instrumental costs were not correlated with accuracy, $r=-.06, p=.37$, corroborating previous research (Flynn \& Lake (Bohns), 2008).

\section{Study 2}

Study 1 demonstrated that help-seekers in China were more accurate at predicting compliance (i.e., they correctly predicted greater compliance) than help-seekers in the U.S. We hypothesized that this effect was due to differences in collectivistic orientation between the two cultures, which led our Chinese help-seekers to rate the social costs of saying 
"no" to a request to be greater than did American help-seekers. However, it is plausible that this effect was driven by other cross-cultural differences between our samples. To garner more confidence that our findings specifically reflect differences in individualistic versus collectivistic orientations, we capitalized on existing within-culture variations in these constructs (e.g., Triandis, 2001). Specifically, we measured individual differences in individualistic and collectivistic orientations in a sample of Americans and looked at whether these orientations were associated with expectations of compliance. Although this design did not allow us to look at prediction accuracy (absent a measure of actual compliance), Study 1 and previous research suggest that people tend to err in the direction of underestimating compliance with direct requests; thus, higher estimates of compliance are generally more accurate. We also tested our proposed mediator once again, along with three alternative hypotheses.

\section{Procedure}

We administered an established scale for measuring individual differences in individualism $(\alpha=.75)$ and collectivism ( $\alpha=.78$; Triandis \& Gelfand, 1998) to 78 American participants (47 female; $M_{A g e}=36$ ) recruited online through Amazon Mechanical Turk.

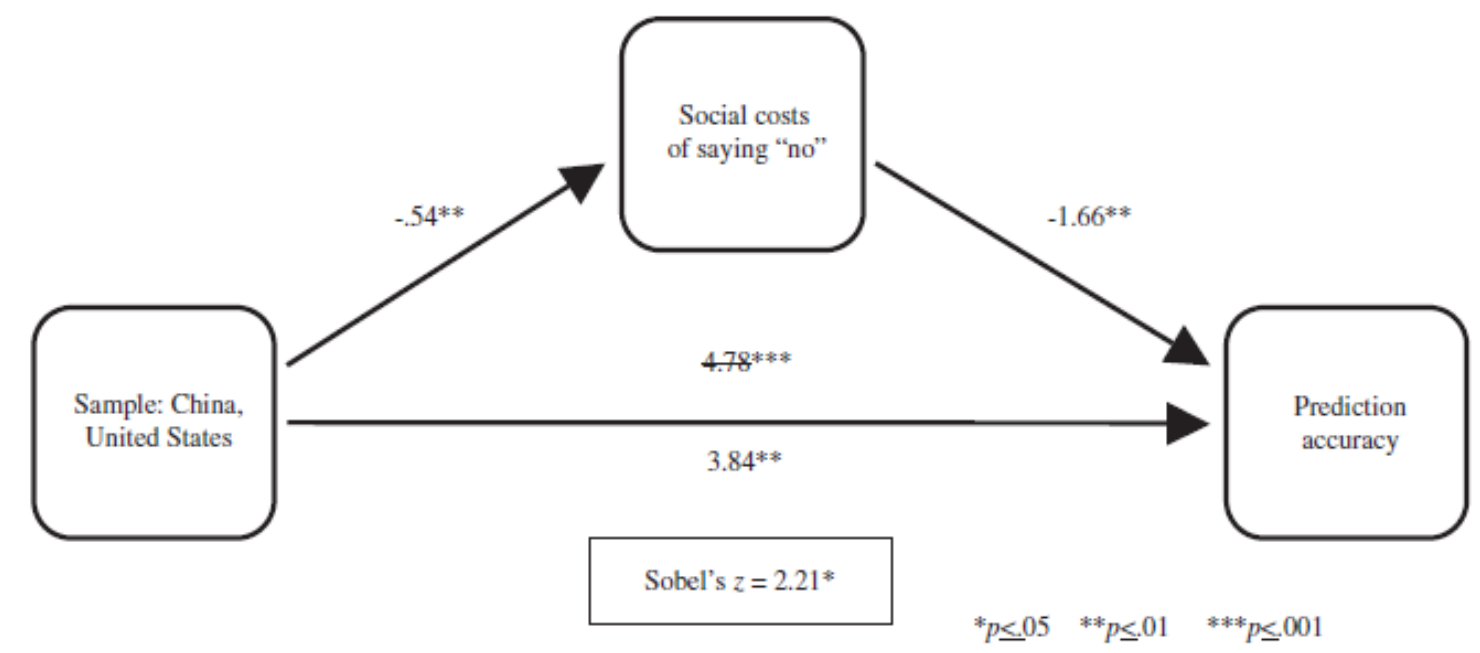

Fig 2 Perceived social costs of saying "no" mediate cross-cultural differences in help-seekers' prediction accuracy in Study 1. (All reported regressions include actual compliance as a covariate).

Although the Triandis and Gelfand measure includes subscales for horizontal and vertical individualism and collectivism, the previous research from which our predictions were drawn (e.g., Kim et al., 2006) does not typically distinguish between these dimensions. Thus, because there was no obvious theoretical basis for making this distinction, all reported analyses are collapsed across the horizontal and vertical dimensions of individualism and collectivism.

In a separate section of the online questionnaire, participants were instructed to imagine themselves approaching strangers in order to solicit donations for an organization of their choosing. They then provided a free-response answer to the following question as our measure of predicted compliance: "If you were to approach 15 people with a request to donate to this organization, how many of those 15 people do you think would agree to make a donation?" Participants also responded to the four "social costs of saying 'no'" items from Study 1 (difficult, embarrassed, bad, awkward; ( $\alpha=.90)$. 
And we included three items to rule out plausible alternative hypotheses. First, it is possible that more collectivistic helpseekers, rather than being more attuned to their targets' perspectives, are more aware of social norms of compliance. A second possibility is that collectivism is related to request directness, which could influence compliance expectations. Finally, a third possibility is that collectivism is related to perceptions of help-seeking as an imposition. To explore these alternative hypotheses, we had participants rate how appropriate it would be for someone to agree to their requests, how direct they imagined their requests to be, and how much of an imposition they considered their requests to be.

\section{Results}

We expected collectivism to be positively associated with ratings of the social costs of saying "no," resulting in higher expectations of compliance. To test this prediction, we calculated collectivism and individualism scores for each participant and regressed predicted compliance (the number of people participants expected to comply with their requests; $M=5.68, S D=3.27$ ) on each of these scores individually. (All reported effects hold when both individualism and collectivism are included in the analyses.) As hypothesized, collectivism was positively associated with predicted compliance, $\beta=1.14, t(77)=2.87, p=.005$ (individualism was not, $\beta=.57, t(77)<1.5)$. Collectivism was also positively associated with perceived social costs of saying "no," $\beta=.60, t(77)=3.75, p<.001$ (again, individualism was not, $\beta=.08, t$ (77)<.5). Mediation analyses (Fig. 3; Baron \& Kenny, 1986) confirmed that perceptions of the social costs of saying "no" mediated the association between collectivism and predicted compliance, $z=3.24, p=.001$.

This association was not explained by any of our alternative hypothesis variables. Collectivism was less strongly associated with appropriateness, $B=.34, \mathrm{t}(77)=2.28, p=.03$, than was individualism, $\beta=.75, \mathrm{t}(77)=5.24, p<.001$. Neither individualism nor collectivism was significantly associated with request directness or how imposing the request was perceived to be (all t's<1.5). Moreover, appropriateness, directness, and imposition were not significantly associated with predicted compliance (all t's<2). Finally, when appropriateness, directness, imposition, social costs, and collectivism were all regressed on predicted compliance within the same model, the only significant effect to emerge was the social costs variable, $B=1.51, t(73)=6.30, p<.001$ (all other $t^{\prime} s<1.6$ ).

\section{Discussion}

In a naturalistic help-seeking study, we found that Chinese help-seekers were more accurate at predicting compliance than American help-seekers. Specifically, Chinese help-seekers correctly expected more people to comply with their requests. Further, this difference in prediction accuracy was mediated by the extent to which Chinese help-seekers took into account the social costs targets would incur by saying "no" to a request. In a supplementary scenario study, we measured individual differences in individualistic and collectivistic orientations and found additional support for an association between collectivism and ratings of the social costs to targets of saying "no" to a request. As in Study 1 , this association resulted in higher expectations of compliance.

We have proposed that our findings reflect the cross-cultural attenuation of an egocentric bias, which led collectivists in our studies to more fully account for the social costs of saying "no" when predicting others' compliance behavior. Previous research suggests that the original underestimation of compliance effect is indeed egocentric in nature (Flynn \& 
Lake (Bohns), 2008, Studies 4 \& 5). Further, Wu and Keysar (2007) have shown that collectivists are better perspectivetakers than individualists, which supports the interpretation that collectivists were better at perspective-taking in the current studies. However, because we did not directly manipulate or measure perspective-taking, there may still be viable alternative explanations. It is possible that collectivists hold different beliefs about whether people should help, or whether people are generally inclined to help (e.g., Miller \& Ratner, 1998), which could affect their estimates of the social costs of saying "no." Although the results of Study 2 suggest that our reasoning fits the data better than an explanation based on "appropriateness," this variable alone cannot definitively rule out a norm-based interpretation.

This work also relates to previous research showing that collectivists are similarly more accurate at predicting their own behavior in helping contexts. Specifically, collectivists were less likely to overestimate their own generosity (Balcetis, Dunning, \& Miller, 2008). Although the proposed mechanism for how collectivism and individualism relate to selfpredictions of generosity is different from the mechanism we propose here, the similarities between these findings suggest that collectivists may likewise be more accurate at predicting the influence of social costs on their own compliance behavior.

Potential avenues for future research include unpacking more precisely these "social costs" that help-seekers are neglecting to greater or less degrees. The same phenomenological experience of feeling too embarrassed to say "no" may reflect different values crossculturally, e.g., Chinese targets' discomfort may reflect fears of others' negative

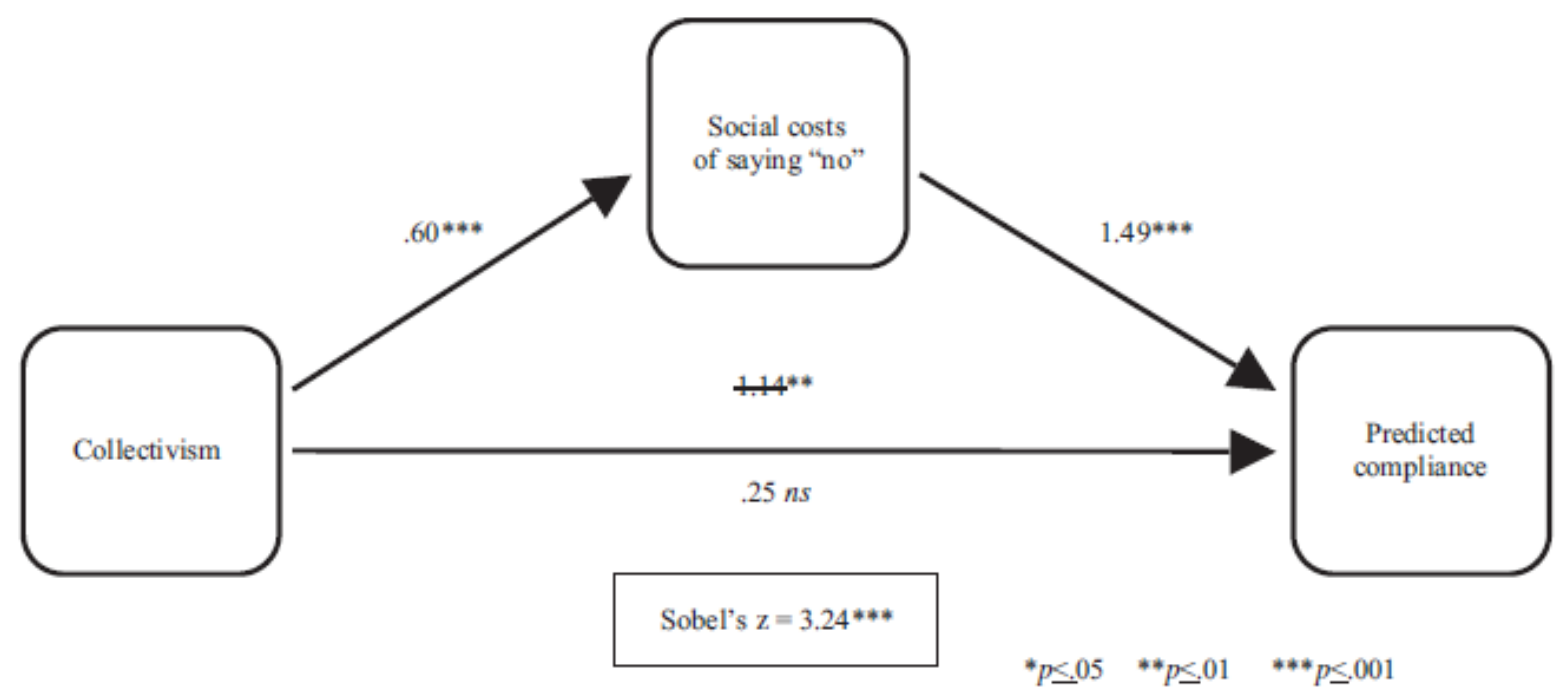

Fig. 3. Perceived social costs of saying "no" mediate the association between collectivism and predicted compliance in Study 2.

judgments (e.g., Heine, Takemoto, Moskalenko, Lasaleta, \& Henrich, 2008), while American targets may be more concerned with self-image. In addition, the current work examined seeking help from strangers, while most previous work on cross-cultural help-seeking has studied help-seeking within close relationships (e.g., Kim et al., 2006). Thus, another area for future research is the potential moderating role that relationship closeness, including perceptions of targets as ingroup versus outgroup members, may have on help- seekers' ability to predict the behavior of potential helpers. 


\section{References}

Asch, S.E.(1956). Studies of independence and conformity: A minority of one against a unanimous majority. Psychological Monographs, 70,1 -70.

Balcetis, E., Dunning, D., \& Miller, R. L. (2008). Do collectivists know themselves better than individualists? Cross-cultural studies of the holier than thou phenomenon. Journal of Personality and Social Psychology, 95,1252-1267.

Baron, R. M., \& Kenny, D. A. (1986). The moderator -mediator variable distinction in social psychological research: Conceptual, strategic, and statistical considerations. Journal of Personality and Social Psychology, 51,1173-1182.

Bohns, V. K., \& Flynn, F. J. (2010). Why didn't you just ask? Underestimating the discomfort of help-seeking. Journal of Experimental Social Psychology, 46, 402-409.

Flynn, F. J., \& Lake (Bohns), V. K. B. (2008). If you need help,just ask: Underestimating compliance with a direct request for help. Journal of Personality and Social Psychology, 95,128-143.

Goffman, E. (1967). Interaction rituals: Essays on face to face interaction. NY: Anchor.

Grice, H. P. (1975). Logic and conversation. In P. Cole, \& J. Morgan (Eds.), Syntax and Semantics, Volume 3. (pp. 41-58)New York: Academic Press.

Heine, S. J., Takemoto, T., Moskalenko, S., Lasaleta, J., \& Henrich, J. (2008). Mirrors in the head: Cultural variation in objective self-awareness. Personality and Social Psychology Bulletin, 34, 879-887.

Kim, H., \& Markus, H. R. (1999). Deviance or uniqueness, harmony or conformity? A cultural analysis. Journal ofPersonality and Social Psychology, 77, 785-800.

Kim, H. S., Sherman, D. K., Ko, D., \& Taylor, S. E. (2006). Pursuit of comfort and pursuit of harmony: Culture, relationships, and social support seeking. Personality and Social Psychology Bulletin, 32,1595-1607.

Kim, H. S., Sherman, D. K., \& Taylor, S. E. (2008). Culture and social support. The American Psychologist, 63, 518-526.

Markus, H. R., \& Kitayama, S. (1991). Culture and the self: Implications for cognition, emotion, and motivation. Psychological Review, 98, 224-253.

Milgram, S. (1963). Behavioral study of obedience. Journal of Abnormal and Social Psychology, 67,371-378.

Miller, D. T., \& Ratner, R. K. (1998). The disparity between the actual and assumed power of self-interest. Journal of Personality and Social Psychology, 74, 53-62.

Sabini, J., Siepmann, M., \& Stein, J. (2001). The really fundamental attribution error in social psychological research. Psychological Inquiry, 12,1-15.

Sobel, M. E. (1982). Asymptotic confidence intervals for indirect effects in structural equation models. Sociological Methodology, 13, 290-312.

Triandis, H. C. (1995). Individualism and collectivism. Boulder, CO: Westview Press.

Triandis, H. C. (2001). Individualism -collectivism and personality. Journal of Personality, 69, 907-924.

Triandis, H. C., \& Gelfand, M. (1998). Converging measurement of horizontal and vertical individualism and collectivism. Journal ofPersonality and Social Psychology, 74,118-128.

Van Boven, L., Loewenstein, G., \& Dunning, D. (2005). The illusion of courage in social predictions: Underestimating the impact of fear of embarrassment on other people. Organizational Behavior and Human Decision Processes, 96, 130-141.

Wu, S., \& Keysar, B. (2007). The effect of culture on perspective taking. Psychological Science, 18, 600-606. 